Araştırma Makalesi / Research Article

Toprak Bilimi ve Bitki Besleme /

Soil Science and Plant Nutrition
Iğdır Üniversitesi Fen Bilimleri Enstitüsü Dergisi, 9(4): 2336-2345, 2019

Journal of the Institute of Science and Technology, 9(4): 2336-2345, 2019

DOI: 10.21597/jist.523076

ISSN: 2146-0574, eISSN: 2536-4618

Türkiye’de Rüzgâr Erozyonuna Bağlı Toprak Kayıplarının Konumsal ve Zamansal Değişiminin Tahmin Edilmesi

Kenan İNCE ${ }^{*}$, Reşat AKGÖZ², Günay ERPUL ${ }^{2}$

ÖZET: Küresel 1sınma ve iklim değişikliğine bağlı olarak kuraklı̆̆ın ciddi bir arazi tahribatına neden olduğu bölgelerde, Sürdürülebilir Toprak Yönetimi (STY) ve Sürdürülebilir Arazi Yönetiminin (SAY) etkin bir şekilde uygulanamaması durumunda, rüzgâr erozyonunun etki alanını ve şiddetini giderek artırması beklenmektedir. $\mathrm{Bu}$ kapsamda farklı konumsal ve zamansal ölçeklerde model tabanlı rüzgâr erozyonu tehlikesi tahmin haritalarının üretilmesi büyük önem taşımaktadır. Bu çalışma ile rüzgâr erozyonu dinamikleri, kurak ve yarı kurak havzalar temelinde ulusal ölçekte değerlendirilerek karar vericiler için daha somut bir planlama veri tabanı olarak kullanıma hazır hale getirilmiş ve çok daha küçük alan ölçeğinde çalışma yapan araştırmacılar için de önemli bir uygulama altlığı olarak kullanıma sunulmuştur. Ulusal ölçekte rüzgâr erozyonunun tahmin edilebilmesi için kapsamlı, dinamik ve güncellenebilir veri kümeleri toplanmış ve Yenilenmiş Rüzgâr Erozyonu Eşitliği (Revised Wind Erosion Equation [RWEQ]) kullanılarak bir tahmin sistemi inşa edilmiştir. RWEQ modeline ait ana parametreler ve bunlara bağlı alt bileşenler matematiksel olarak analiz edilmiş ve Türkiye ölçeğinde rüzgâr erozyonu sonucu taşınan sediment miktarı ve rüzgâr erozyonunun etkilediği alanlara ait ara sonuçlar başarıyla üretilmiştir. Böylece aylık ve yıllık toprak kayıplarını tahmin etmek için 30mx30m mekânsal çözünürlükle üretilen model sonuçları yardımıyla STY ve SAY uygulamalarının stratejik olarak önceliklendirileceği alanlar belirli istatistiksel değişim aralığ içerisinde belirlenmiştir.

Anahtar Kelimeler: Rüzgâr Erozyonu, RWEQ Modeli, Zamansal ve Mekânsal Analiz

\title{
Predicting Spatial and Temporal Changes in Soil Loss by Wind Erosion in Turkey
}

ABSTRACT: In areas where drought has caused serious land degradation due to global warming and climate change, the inability to effectively implement the Sustainable Soil Management (SSM) and the Sustainable Land Management (SLM) is very likely to result in increased impact and intensity of wind erosion. In this context, the production of model-based estimation maps for wind erosion hazard at different spatial and temporal scales are more important. With this study, by assessing the wind erosion dynamics at a national scale on the basis of arid and semi-arid basins, a more concrete planning database for decision makers was prepared, readily available as an applicative map layer as well for the researchers working at a much smaller scales. For estimating wind erosion at the national scale, comprehensive, dynamic and updatable data sets were collected and a predictive system was constructed by using the Revised Wind Erosion Equation (RWEQ). The principal parameters and related sub-components of the RWEQ model were analyzed mathematically; and the amount of sediment transported by the wind erosion processes and interim results for the areas affected by the wind erosion were successfully predicted and produced at the national scale in Turkey, respectively. Thus, by means of using the model results designed to produce $30 \mathrm{mx} 30 \mathrm{~m}$ spatial resolution to estimate the monthly and annual soil losses, the potential areas where the SSM and SLM applications would be strategically prioritized were determined within a certain statistical change interval.

Keywords: Wind Erosion, RWEQ Model, Temporal and Spatial Analysis

\footnotetext{
${ }^{1}$ Kenan İNCE (Orcid ID: 0000-0002-7555-0248), T.C. Tarım ve Orman Bakanlığı, Çölleşme ve Erozyonla Mücadele Genel Müdürlüğü, Ankara,

2 Reşat AKGÖZ (Orcid ID: 0000-0002-4618-4103), Günay ERPUL (Orcid ID: 0000-0002-3797-6969), Ankara Üniversitesi, Ziraat Fakültesi, Toprak Bilimi ve Bitki Besleme Bölümü, Ankara

*Sorumlu Yazar / Corresponding Author: Kenan INCE, e-mail: kenan.ince@tarimorman.gov.tr 


\section{GİRIŞ}

Yapılan çalışmalara göre dünya genelinde 432.2 milyon ha'lık bir alanın rüzgâr erozyonu tehlikesi ile karşı karşıya olduğu ve bu alanların kıtalara, iklim koşullarına vb. göre farklılık gösterdiği belirtilmektedir (Zobeck ve ark., 2014).

Avrupa Birliğine üye 28 ülke için yürütülen rüzgâr erozyonu çalışmalarına göre ise ekilebilir tarım alanlarının \%9.70'nin orta ve yüksek derecede rüzgâr erozyonundan etkilendiği ortaya konulmuştur (Borrelli ve ark., 2016).

Saha ölçümleri ve gözlemlere bağlı olarak yürütülen çalışmalara göre de, Türkiye'de hafiften çok şiddetliye kadar değişen oranlarda yaklaşık 500 bin ha alanda rüzgâr erozyonunun yaşandığı ifade edilmiştir. Bu alanın da yaklaşık \%70'inin Konya ili sınırları içerisinde olduğu belirtilmiştir (Acar ve Dursun., 2010). Diğer bir çalışmaya göre ise, sadece Karapınar'da 100 bin ha alanın rüzgâr erozyonundan etkilendiği belirtilmiştir (Okur, 2010).

Türkiye'de elde edilen değerler ortalama olarak verilmekte ve herhangi bir yönteme veya modele dayalı olarak alt havza, havza veya bölge ölçeğinde konumsal dağılıma ait ayrıntılı bir bilgi sunamamaktadır. Yine rüzgâr erozyonunun yıl-içi ve yıllar-arası konumsal ve zamansal dağılımı konusunda birkaç çalışma dışında ( Başaran ve ark., 2017), pek fazla bir istatistik bulunmamaktadır.

Olası erozyon tehditlerinin doğru senaryolar altında tahmin edilmesi, hem belirli istatistiklerin üretilmesi hem de koruyucu Sürdürülebilir Toprak Yönetimi (STY) ve Sürdürülebilir Arazi Yönetimi (SAY) uygulamaları açısından önemli görülmektedir. İyi uygulamaların etkinlikle yaygınlaştırılması için yapılacak değerlendirmelerin noktasal değil de bölgesel veya ülke ölçeğinde gerçekleştirilmesi ayrıca ehemmiyet taşımaktadır.

Gıda güvenliği ile çok yakından alakalı olarak başta tarım alanları olmak üzere, Türkiye'de iklim değişimi sonucu kuraklık tehlikesinin arttığ1 ve buna paralel biçimde rüzgâr erozyonu şiddetinin ve etkilediği alan miktarının da arttığ yakın dönemde gözlenmektedir. Bu maksatla ulusal ölçekte rüzgâr erozyonu sonucu taşınan sediment miktarının model tabanlı olarak izleme ve değerlendirmesine yönelik eksikliğin giderilmesi amacıyla, Çölleşme ve Erozyonla Mücadele Genel Müdürlüğü (ÇEMGM) tarafindan RWEQ model yapısını (Fryrear ve ark., 2000) esas alan izleme ve değerlendirme çalışmaları 2016 yılında başlatılmıştır. Böylece, Türkiye'de rüzgâr erozyonu potansiyeline sahip alanlar ile rüzgâr erozyonuna maruz kalan alanların dinamik bir sistemle tespit edilmesi mümkün bir hale gelmiştir. Elde edilecek sonuçlar yardımıyla, bu alanlarda alınacak önlemlerin belirlenmesinde ilgili planlayıcı devlet kuruluşlarınca da kullanılmak üzere sürekli güncellenebilir bir doğal kaynak veri tabanı oluşturulmuştur.

Bu çalışmada ana havzalar, alt havzalar ve mikro havzalar ölçeğinde, bir model hesaplama ve tahmin yöntemine dayalı rüzgâr erozyonu tehlikesinin hem konumsal hem de zamansal dağılımı belirli istatiksel değişim aralığı ile harita yüzeyleri şeklinde üretilmiştir.

\section{MATERYAL VE YÖNTEM}

Ulusal Dinamik Rüzgâr Erozyonu Modeli ve İzleme Sistemi (UDREMİS), ülkesel düzeyden mikro havza ölçeğine kadar değişen boyutlarda, rüzgâr erozyonunun şiddeti ve etkilediği alan miktarı üzerinde zamansal izleme ve değerlendirme yapmaktadır.

\section{Çalışma Alanı}

Türkiye'de düz ve düze-yakın yaklaşık 17 milyon ha alan model tabanlı olarak rüzgâr erozyonu izleme ve değerlendirme analizleri için çalışılmıştır (İnce ve ark., 2018). Ayrıca, bu alanlardaki ortalama işletme büyüklüğü (Boztoprak, 2015) için $\geq 6$ hektarlık bir alan en küçük planlama birimi olarak kabul edilmiştir. 
Yenilenmiş Rüzgâr Erozyonu Eşitliği Modeli (RWEQ)

RWEQ rüzgâr erozyon modeli, dört ana parametre ve ilişkili alt parametreleri hesaplayarak birim alandan taşınan potansiyel sediment miktarını $\left(\mathrm{kg} \quad \mathrm{m}^{-2} \quad \mathrm{y}^{-1}{ }^{-1}\right)$ tahmin etmektedir (Şekil 1).

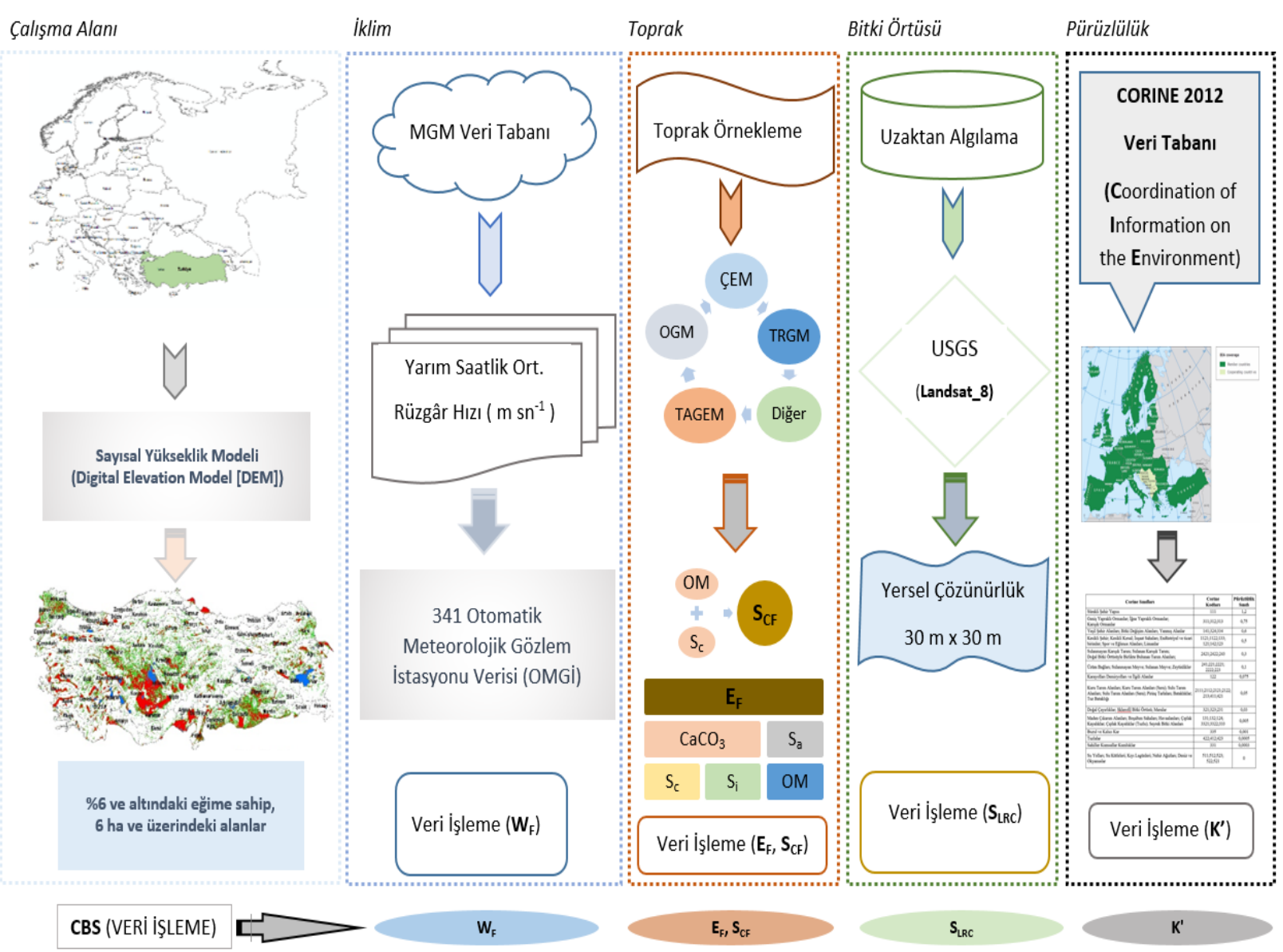

Şekil 1. RWEQ modeli ana parametrelerine ait veri tabanları

RWEQ modeli, diğer taşınma eşitliklerinde olduğu gibi, ya sürtünme hızının küpünü ya da referans yükseklikteki rüzgâr hızının küpünü kullanmaktadır. Eşik rüzgâr hızlarını hesaplamak ve tanımlamak için de $2 \mathrm{~m}$ yükseklikteki $5 \mathrm{~m} \mathrm{~s}^{-1}$ değerindeki bir rüzgâr hızını, model eşik rüzgâr hızı olarak kabul etmektedir (İnce, 2017; İnce ve ark., 2018). Bu çalışmada Eşitlik 1., 2., 3. ve 4. (Borrelli ve ark., 2016) RWEQ hesaplamalarında temel altlık olarak kullanılmıştır (Şekil 2).

$\mathrm{Q}_{\mathrm{x}}=\mathrm{Q}_{\max }\left[1-\mathrm{e}^{-\left(\frac{\mathrm{x}}{\mathrm{s}}\right)^{2}}\right]$

Burada $\mathrm{Q}_{\mathrm{x}}, \mathrm{x}$ Mesafesinde Toplam Taşınan

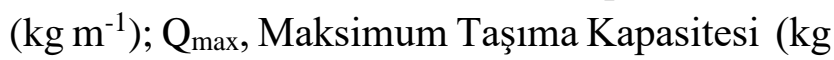
$\left.\mathrm{m}^{-1}\right)$; $\mathrm{x}$, Alanın aşınmaz kenarından rüzgâr erozyonuna olan uzaklığ $1(\mathrm{~m})$ ve $\mathrm{s}$, Maksimum taşıma kapasitesinin \%63'üne ulaşma noktası, kritik alan uzunluğudur (m).

$\mathrm{S}_{\mathrm{L}}=\frac{2 \mathrm{x}}{\mathrm{s}^{2}} \mathrm{Q}_{\max } \mathrm{e}^{-\left(\frac{\mathrm{x}}{\mathrm{s}}\right)^{2}}$

$\mathrm{Q}_{\max }=109.8\left(\mathrm{~W}_{\mathrm{F}} * \mathrm{E}_{\mathrm{F}} * \mathrm{~S}_{\mathrm{CF}} * \mathrm{~K}^{\prime} * \mathrm{~S}_{\mathrm{LRC}}\right)$

$\mathrm{s}=150.71\left(\mathrm{~W}_{\mathrm{F}} * \mathrm{E}_{\mathrm{F}} * \mathrm{~S}_{\mathrm{CF}} * \mathrm{~K}^{\prime} * \mathrm{~S}_{\mathrm{LRC}}\right)^{-0.3711}$

Burada $\mathrm{S}_{\mathrm{L}}$, Toprak Kayb1 $\left(\mathrm{kg} \mathrm{m}^{-2}\right)$; $\mathrm{W}_{\mathrm{F}}$, Rüzgâr Erozyonu İklim Faktörü; $\mathrm{E}_{\mathrm{F}}$, Toprağın Rüzgâr Erozyonuna Duyarlılık Faktörü; $\mathrm{S}_{\mathrm{CF}}$, Rüzgâr Erozyonu Toprak Kabuklanma Faktörü; K', Toprak Pürüzlülüğü Faktörü ve $S_{\text {LRC }}$, Bileşke Ürün Faktörünü ifade etmektedir. 
RWEQ Modeli Ana ve Alt seti olarak değerlendirilebilecek 332 adet Parametrelerinin Elde Edilmesi ve Otomatik Meteorolojik Gözlem İstasyonuna Değerlendirilmesi (OMGI) ait yarım saatlik ortalama rüzgâr

RWEQ modeli için gerekli ana hızlarından elde edilmiştir (Eşitlik 5.). parametrelerden iklime ait olan Rüzgâr Erozyonu İklim Faktörü ( $\mathrm{W}_{\mathrm{F}}, \mathrm{kg} \mathrm{m}^{-1}$ ) tüm Türkiye'de farklı $\mathrm{W}_{\mathrm{F}}=\frac{\sum_{\mathrm{i}=1}^{\mathrm{N}} \mathrm{U}_{2}\left(\mathrm{U}_{2}-\mathrm{U}_{\mathrm{t}}\right)^{2} \times \mathrm{N}_{\mathrm{d}} \rho}{\mathrm{N} \times \mathrm{g}} \times \mathrm{S}_{\mathrm{W}} \times \mathrm{S}_{\mathrm{D}}$ noktalarda konumlandırılmış ve uzun yıllar veri
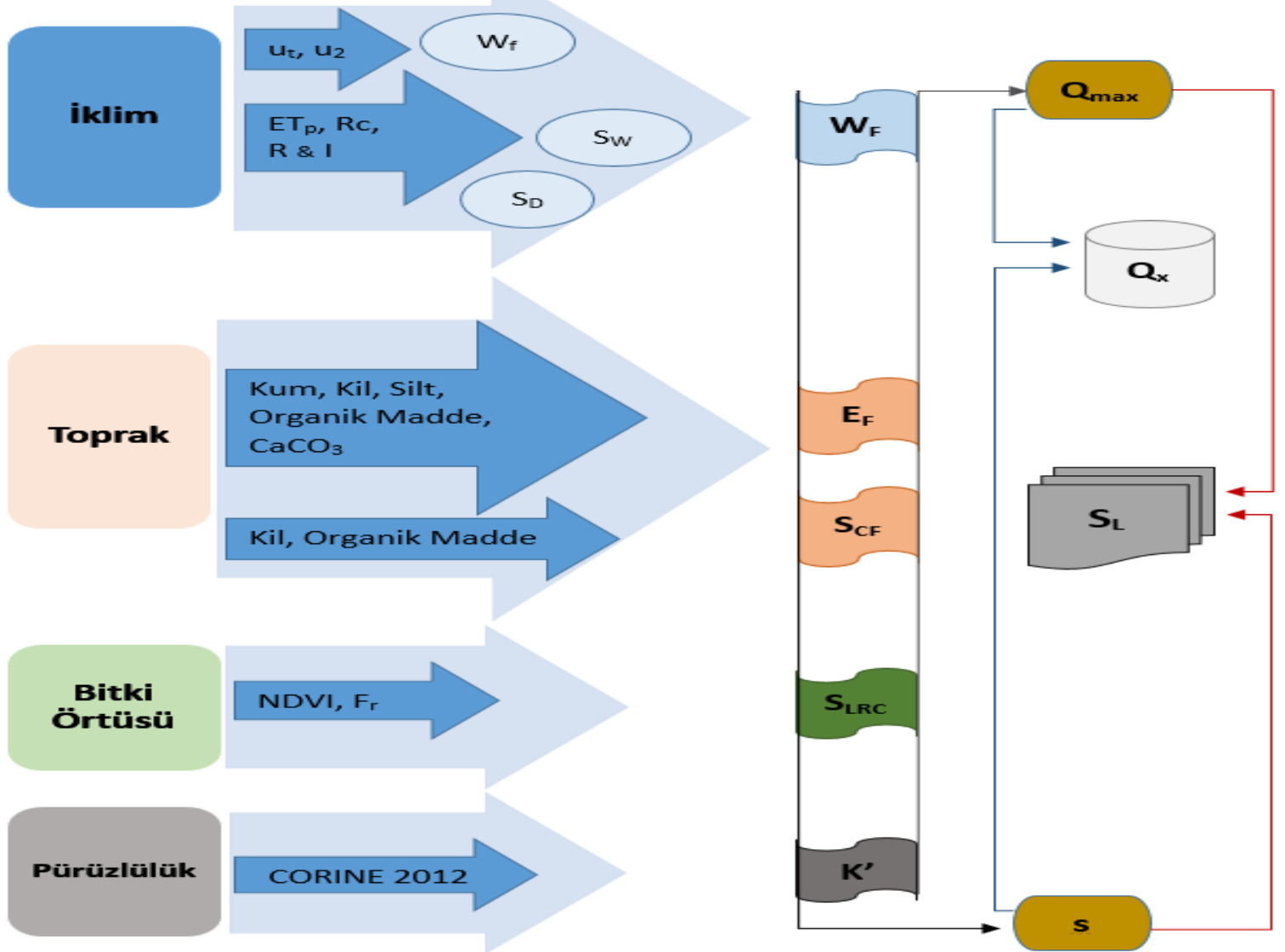

Şekil 2. RWEQ model yapısı ana ve alt parametreleri ile eşitlik hesaplamaları akış şeması (Fryrear ve ark., 1998; Youssef ve ark., 2012)

Burada u 2,2 m Yükseklikteki Rüzgâr Hızı $\left(\mathrm{m} \mathrm{s}^{-1}\right)$; $\mathrm{u}_{\mathrm{t}}, 2 \mathrm{~m}$ Yükseklikteki Eşik Rüzgâr Hızı $\left(\mathrm{m} \mathrm{s}^{-1}\right)$; N, Rüzgâr Hız Gözlemlerinin Sayısı; $\mathrm{N}_{\mathrm{d}}$, İlgili Zaman Aralığındaki Günlerin Sayısı; $\rho$, Hava Yoğunluğu $\left(\mathrm{kg} \mathrm{m}^{-3}\right)$; g, Yerçekimi İvmesi $\left(\mathrm{m} \mathrm{s}^{-2}\right) ; \mathrm{S}_{\mathrm{W}}$, Toprak Islaklığ (birimsiz) ve $\mathrm{S}_{\mathrm{D}}, \mathrm{Kar}$ Örtüsü Faktörünü ifade etmektedir.
RWEQ modeli esas alınarak yürütülen çalışmalarda WF'ye bağlı olarak toprak kayıplarının Şubat, Mart ve Nisan aylarında zirvede olduğu ve ilkbaharla birlikte aylık toprak kaybı değerlerinin bitki örtüsüne bağlı olarak düştüğü ortaya konulmuştur (İnce ve ark., 2018). 


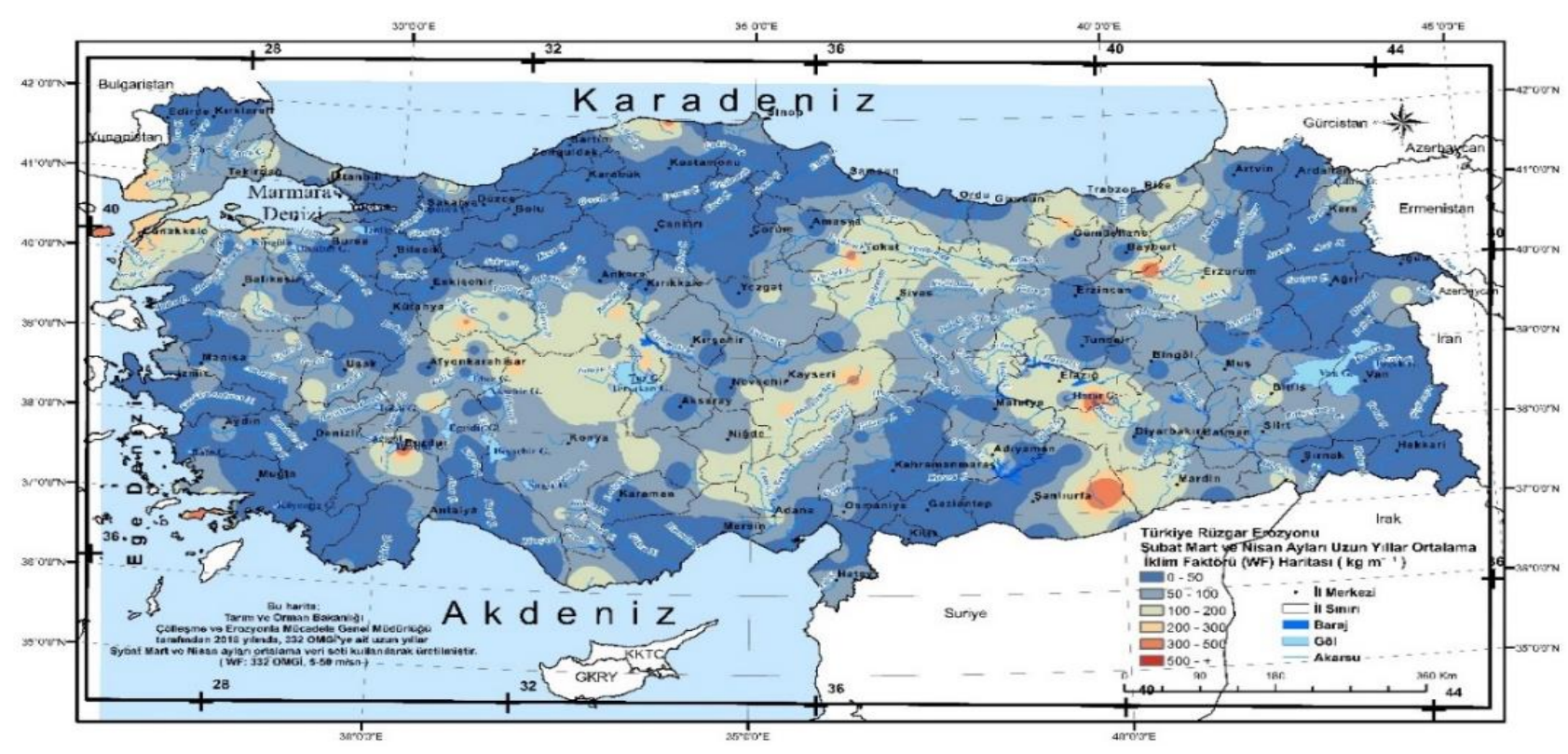

Şekil 3. Türkiye uzun yıllar şubat-mart-nisan ayları ortalama $\mathrm{W}_{\mathrm{F}}\left(\mathrm{kg} \mathrm{m}^{-1}\right)$ haritası

Ay bazında ayrı ayrı değerlendirme yapılabilmesinin yanında bu çalışmada $\mathrm{W}_{\mathrm{F}}$ faktörünün aylık ortalama en yüksek değerlere sahip olduğu uzun yıllar Şubat, Mart ve Nisan ayları ortalama verileri kullanılarak gerekli hesaplamalar yapılmıştır (Şekil 3).

Toprağın Rüzgâr Erozyonuna Duyarlılık Faktörü $\left(\mathrm{E}_{\mathrm{F}}\right)$ ile yine toprak faktörü içerisinde değerlendirilen Rüzgâr Erozyonu Toprak Kabuklanma Faktörü $\left(\mathrm{S}_{\mathrm{CF}}\right)$ 'nin hesaplanmasında farklı kurum ve kuruluşlar tarafından elde edilmiş koordinatlı, noktasal 14801 toprak yüzey örneklemlerine ait veri kümesi kullanılmıştır (Çizelge1) (İnce ve ark., 2019).

Çizelge 1. Türkiye topraklarının $E_{F}$ ve $S_{C F}$ değerlerine ait korelasyon sonuçları karşılaştırma çizelgesi (İnce ve ark., 2019)

\begin{tabular}{|c|c|c|c|c|}
\hline Korelasyon & $\begin{array}{c}\text { E }_{F_{-}} \text {Hesaplanan- } \\
\text { E }_{F_{-}} \text {IDW }\end{array}$ & $\begin{array}{c}\mathbf{E}_{\mathrm{F} \_ \text {Hesaplanan- }} \\
\mathbf{E}_{\mathrm{F} \_ \text {Kriking }}\end{array}$ & $\begin{array}{c}\text { S }_{\text {CF_Hesaplanan- }} \text { - } \\
\text { S }_{\text {CF_IDW }}\end{array}$ & $\begin{array}{c}\mathbf{S}_{\mathrm{CF} \_H e s a p l a n a n-} \\
\mathbf{S}_{\mathrm{CF} \_ \text {Kriking }}\end{array}$ \\
\hline Pearson & 0.558 & 0.561 & 0.458 & 0.467 \\
\hline Spearman & 0.551 & 0.554 & 0.510 & 0.507 \\
\hline RMSE & 0.110 & 0.109 & 0.172 & 0.166 \\
\hline
\end{tabular}

Rüzgâr Erozyonu Bitki Örtüsü Faktörünün $\left(\mathrm{S}_{\text {LRC }}\right)$ belirlenmesi için USGS (United States Geological Survey) tarafindan 2016 yılında üretilen, 30mx30m mekânsal ve 16 gün zamansal çözünürlüğe sahip Landsat_8 uydu görüntüleri kullanılarak bitki örtüsü kapalılığına bağlı toprak kayıpları oranı belirlenmiştir.

İlgili yıla ait uygu görüntüleri değerlendirilerek sırasıyla Normalize Edilmiş Fark Bitki Örtüsü İndeksleri (Normalized Difference Vegetation Index [NDVI]), vejetasyon (Fr) ve toprak kayıları oranı ( $\left.\mathrm{S}_{\text {LRC }}\right)(\%)$ belirlenmiştir. Elde edilen uydu görüntülerinden gerekli bantlar kullanılarak ilk aşamada NDVI Eşitlik 6. ya göre elde edilmiştir.

NDVI $=\frac{(\text { Yakın Kızıl Ötesi }- \text { Kırmızı })}{(\text { Yakın Kızıl Ötesi }+ \text { Kırmızı })}$

Ardından hesaplanan NDVI değerleri kullanılarak, Gillies ve ark., (1997) tarafindan geliştirilen (Nathaniel ve Robert, 2003) ve her bir piksel içinde gözlenen vejetasyon oranı (Fr) (\%) Eşitlik 7. e göre hesaplanmıştır.

$\mathrm{Fr}=\left(\frac{\text { NDVI-NDVIs }}{\text { NDVIV-NDVIs }}\right)^{2}$ 
Burada Fr, Vejetasyon Oranı (\%); NDVIs, Ham Toprak Yüzeyi; NDVIv, Bitki Örtüsünü ifade etmektedir.

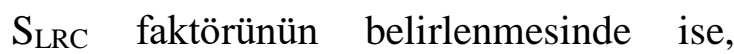
Fryrear ve ark., (2000) tarafindan bildirilen Eşitlik 8. dikkate alınarak bitki örtüsüne bağlı toprak kayıpları oranı $\left(\mathrm{S}_{\mathrm{LRC}}\right)(\%)$ belirlenmiştir.

$\mathrm{S}_{\mathrm{LRC}}=\mathrm{e}^{-5.614\left(\mathrm{Fr}^{0.7366}\right)}$

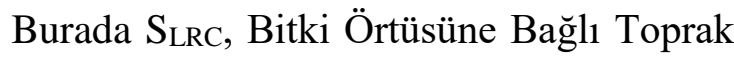
Kayıpları Oranı (\%); Fr, Vejetasyon Oranını (\%) ifade etmektedir.

Son olarak, RWEQ modeli için gerekli olan Arazi Pürüzlülük Faktörünün

$\left(\mathrm{K}^{\prime}\right)$ belirlenmesinde ulusal ölçekte ulaşılabilir veri kaynağı olarak değerlendirilen CORINE (COoRdinate INformation on the Environment) 2012 verisi esas alınmıştır. Buna göre en küçük planlama birimi olan 25 ha için, 44 farklı arazi kullanımında belirlenmiş 14 farklı arazi pürüzlülük katsayı verileri esas alınmıştır (Anonim, 2018). Pürüzlülük katsayıs1 belirlenirken Eşitlik 9. yardımıyla her bir 25 ha'lık altıgen alanı içinde bulunan farklı arazi kullanım alanları, büyüklüklerine göre ağırlıklı olarak hesaplanmış ve tüm altıgenlere ait tek bir pürüzlülük katsayı değeri elde edilmiştir (Şekil 4).

$\mathrm{q}=\frac{\sum_{\mathrm{i}=1}^{\mathrm{n}} \mathrm{K}_{\mathrm{i}} \mathrm{A}_{\mathrm{i}}}{\sum_{\mathrm{i}=1}^{\mathrm{n}} \mathrm{A}_{\mathrm{i}}}$

Burada q, Ağırlıklı Pürüzlülük Katsayısı; K, Uygulama Alanındaki Pürüzlülük Katsayısı ve A, Uygulama Alanının Büyüklügünü (ha) ifade etmektedir. $\mathrm{i}=1 \ldots \mathrm{n}$ ise uygulama alanı içerisindeki emsallerin dikkate alındığı alan büyüklüklerinin sayısını ifade etmektedir.

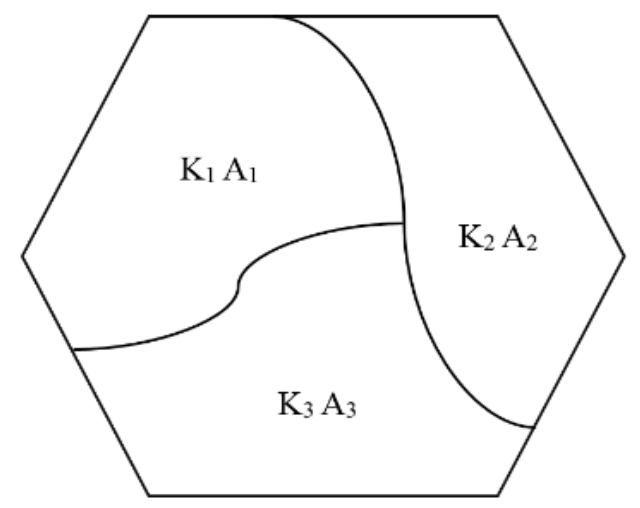

Şekil 4. RWEQ modeli pürüzlülük katsayısının belirlenmesinde kullanılan altıgen yaklaşım şeması

$\mathrm{Bu}$ çalışmada tüm Türkiye'de rüzgâr erozyonu sonucu taşınan sediment miktarının hesaplanabilmesi için gerekli olan ve alanın aşınmaz kenarından rüzgâr erozyonuna olan uzaklığını (m) ifade eden $\mathrm{x}$ değeri $100 \mathrm{~m}$ alınmıştır (Fryrear ve ark., 1999).

\section{BULGULAR VE TARTIŞMA}

UDREMIS yazılımı RWEQ eşitlikleri ile yapılan hesaplamalar ve değerlendirmeler sonucunda, Türkiye'de Rüzgâr Erozyonu Sonucu Taşınan Sediment Miktarı Haritası $\left(\mathrm{kg} \mathrm{m}^{-2} \mathrm{yl}^{-1}\right)$ elde edilmiştir (Şekil 5) .
Her ne kadar kullanılan model alt havza, havza, bölge ve ulusal düzeyde değerlendirme olanağı sunsa da, ilk aşamada, tüm değerlendirmeler ülkesel düzeyde ve maksimum taşınabilecek sediment miktarına yönelik gerçekleştirilmiştir. $\mathrm{Bu}$ nedenle hesaplamalarda maksimum değerin elde edilebilmesi için iklim faktörünün $\left(\mathrm{W}_{\mathrm{F}}, \mathrm{kg} \mathrm{m}^{-1}\right)$ zirvede olduğu Şubat, Mart ve Nisan aylarına ait üç aylık bir ortalama değer esas alınmıştır. Yine maksimum taşınan sediment miktarının ortaya konulabilmesi için, Eşitlik 1. de yer alan ve alanın aşınmaz kenarından rüzgâr erozyonuna olan uzaklığını 
(m) ifade eden $\mathrm{x}$ değerinin maksimum olduğu kabul edilmiştir. Ülkesel düzeyde ilk tahmini sonuçlar üretilirken tüm ülke yüzeyi için bulutluluk oranına bağlı olarak kullanılabilir uydu görüntüleri Mayıs, Haziran ve Temmuz aylarında elde edilebildiği için, bitki örtüsü faktörünün hesaplanmasında bu üç aya ait bütünleşik uydu görüntüsü kullanılmıştır.
Bütün bu yaklaşımlarla elde edilen ve Şekil 5'de gösterilen Türkiye'de Rüzgâr Erozyonu Sonucu Taşınan Sediment Miktarı Haritasına ait sonuçlar geçmiş yıllarda elde edilmiş sonuçlara göre farklılık arz etmektedir. Buna göre topoğrafik açıdan eğiminde etkisiyle Orta Anadolu'nun güneye yakın kısımları ve Güney Doğu Anadolu Bölgesi rüzgâr erozyonu açısından yoğunluklu alanlar olarak karşımıza çıkmaktadır.

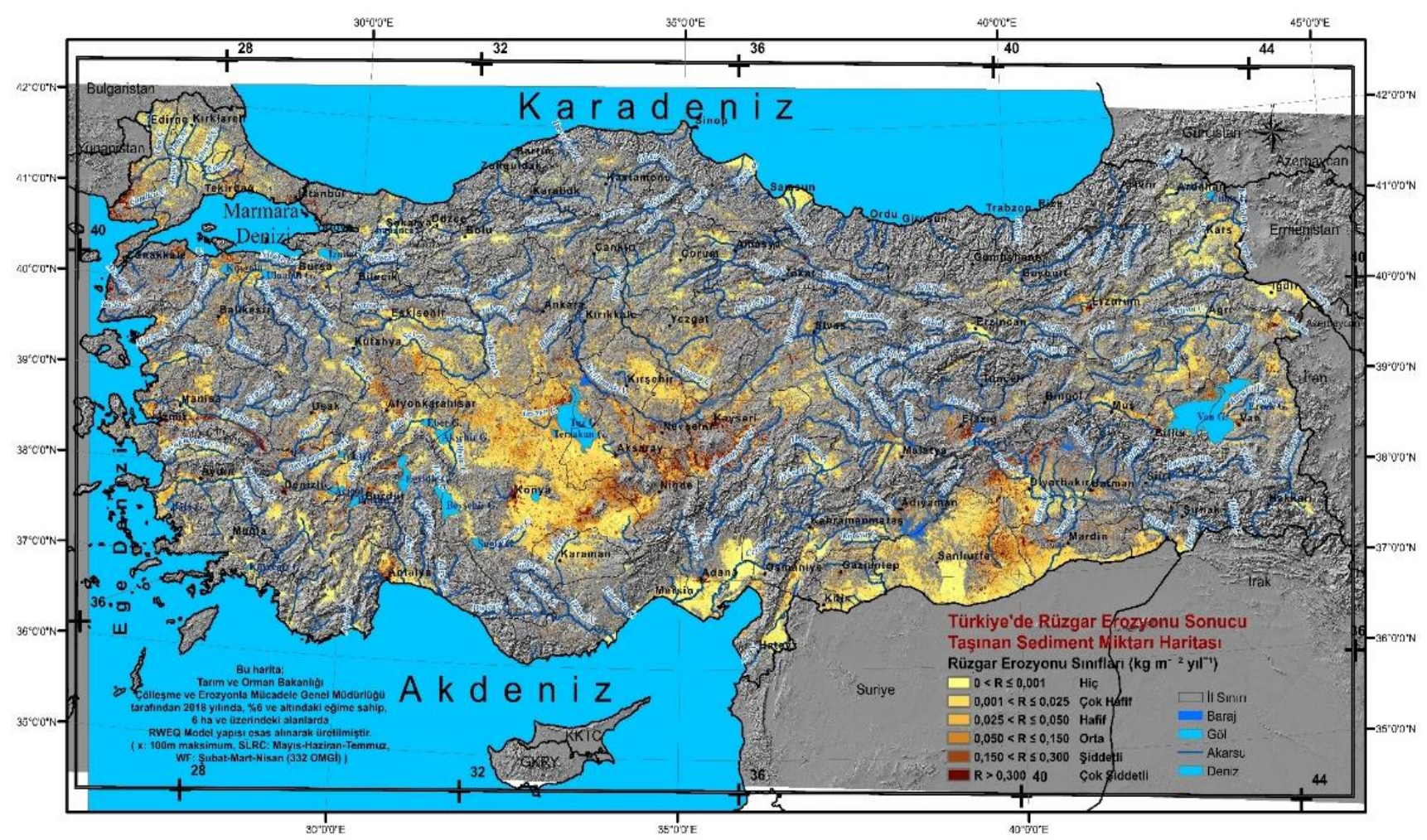

Şekil 5. Türkiye'de rüzgâr erozyonu sonucu taşınan sediment miktarı haritası

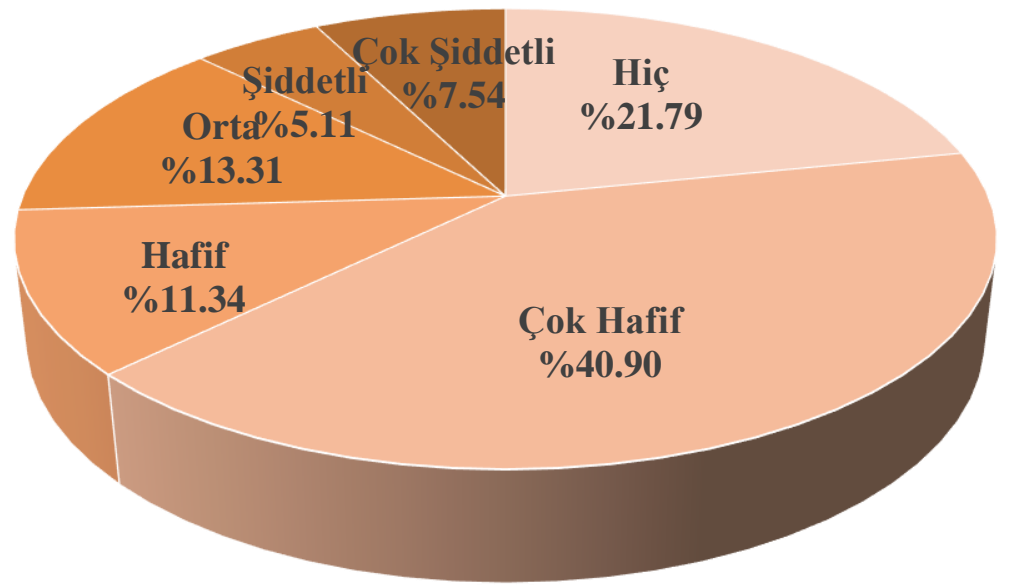

Şekil 6. Türkiye'de rüzgâr erozyonunun şiddet bakımından yüzde dağılım grafiği 
İlk aşama olarak ülkesel düzeyde yapılan mekânsal analizlere göre Şekil 6'da gösterildiği gibi alansal olarak Türkiye'de rüzgâr erozyonu potansiyeline sahip toplam alanın, \%7.54'ünde çok şiddetli rüzgâr erozyonunun yaşanabileceği belirlenmiştir.
Türkiye büyük havzaları teker teker incelendiğinde ise, Çizelge 2'de görüldüğü gibi çok şiddetli rüzgâr erozyonuna en çok sahip alanların sirasiyla Dicle-Firat, Kizılırmak ve Konya havzaları, en az alanların ise sirasiyla Çoruh, Doğu Karadeniz ve Batı Karadeniz havzaları olduğu belirlenmiştir.

Çizelge 2. Ana akarsu havzalarında rüzgâr erozyonu şiddetine bağlı alansal dağılım çizelgesi

\begin{tabular}{|c|c|c|c|c|c|c|}
\hline $\begin{array}{l}\text { Havza Adı / Rüzgâr Erozyonu } \\
\text { Şiddeti }\left(\mathrm{kg} \mathrm{m}^{-2} \mathrm{yll}^{-1}\right)\end{array}$ & $\begin{array}{c}\text { Hiç } \\
(0-0.001)\end{array}$ & $\begin{array}{c}\text { Çok Hafif } \\
(0.001-0.025)\end{array}$ & $\begin{array}{c}\text { Hafif } \\
(0.025-0.05)\end{array}$ & $\begin{array}{c}\text { Orta } \\
(0.05-0.150)\end{array}$ & $\begin{array}{c}\text { Şiddetli } \\
(0.15-0.300)\end{array}$ & $\begin{array}{c}\text { Çok Şiddetli } \\
\quad(>\mathbf{0 . 3 0})\end{array}$ \\
\hline Akarçay & 68266 & 121317 & 30343 & 37222 & 16156 & 19947 \\
\hline Antalya & 84555 & 110873 & 21367 & 34190 & 19530 & 30492 \\
\hline Aras & 282292 & 310321 & 33328 & 25675 & 11195 & 11564 \\
\hline Asi & 72027 & 114180 & 12955 & 20978 & 8092 & 8046 \\
\hline Batı Akdeniz & 124530 & 103720 & 11886 & 13719 & 5256 & 7780 \\
\hline B. Karadeniz & 104090 & 49474 & 8444 & 7760 & 2899 & 3701 \\
\hline Burdur & 15162 & 73513 & 24251 & 30316 & 10622 & 21346 \\
\hline B. Menderes & 121550 & 253623 & 89717 & 85369 & 36060 & 51569 \\
\hline Ceyhan & 295133 & 202724 & 26056 & 22473 & 9762 & 9432 \\
\hline Çoruh & 20943 & 33822 & 4844 & 3700 & 1400 & 1808 \\
\hline Dicle-Firat & 635495 & 1740632 & 448925 & 495919 & 188067 & 265259 \\
\hline Doğu Akdeniz & 61122 & 50856 & 13160 & 19809 & 6469 & 6980 \\
\hline D. Karadeniz & 5476 & 4560 & 1097 & 1578 & 1063 & 3658 \\
\hline Gediz & 52803 & 110979 & 37836 & 51864 & 32182 & 62650 \\
\hline Kızılırmak & 296928 & 668650 & 239262 & 290850 & 115795 & 198444 \\
\hline Konya & 332864 & 1108820 & 416047 & 458985 & 151930 & 156253 \\
\hline Kuzey Ege & 15561 & 75049 & 18799 & 31400 & 20692 & 35644 \\
\hline K. Menderes & 43721 & 50480 & 14429 & 23069 & 10876 & 25688 \\
\hline Marmara & 59399 & 122376 & 37828 & 62763 & 37945 & 82496 \\
\hline Meriç & 210017 & 343916 & 69441 & 74307 & 34011 & 47316 \\
\hline Sakarya & 414099 & 803453 & 243538 & 301827 & 56324 & 70827 \\
\hline Seyhan & 133903 & 119345 & 30109 & 48770 & 32358 & 72347 \\
\hline Susurluk & 81241 & 120525 & 35300 & 53249 & 21632 & 33888 \\
\hline Van Gölü & 38830 & 127962 & 41809 & 43595 & 21107 & 19484 \\
\hline Yeşilırmak & 163930 & 189058 & 32423 & 42202 & 24869 & 46140 \\
\hline$\overline{\Sigma \text { ALAN (ha) }}$ & 3733949 & 7010240 & 1943208 & 2281601 & 876303 & 1292771 \\
\hline
\end{tabular}

Alansal olarak çok şiddetli rüzgâr erozyonunun yaşandığı Dicle-Fırat, Kızılırmak ve Konya havzaları aynı zamanda eğime bağlı olarak rüzgâr erozyonu potansiyeline sahip en büyük havzalar (sırasiyla: 3774300 ha, 180993 ha, 2 624902 ha) olarak da karşımıza çıkmaktadır.
Çok şiddetli rüzgâr erozyonuna sahip (en fazla ve en az alan bakımından) havzalar için RWEQ ana parametreleri Çizelge 3'de ortalama olarak ortaya konulmuştur. 
Çizelge 3. Alansal olarak çok şiddetli rüzgâr erozyonuna sahip en büyük ve en küçük havzaların parametre değerlerine ait çizelge

\begin{tabular}{|c|c|c|c|c|c|}
\hline Havza Adı & $\mathrm{W}_{\mathrm{F}}$ (Ort.) & $E_{F}$ (Ort.) & $\mathrm{S}_{\mathrm{CF}}$ (Ort.) & S LRC (Ort.) & $\mathbf{K}^{\prime}$ (Ort.) \\
\hline Dicle / Furat & 93.56 & 0.41 & 0.11 & 0.57 & 0.08 \\
\hline Kızılırmak & 76.51 & 0.40 & 0.20 & 0.43 & 0.09 \\
\hline Konya & 86.46 & 0.32 & 0.21 & 0.53 & 0.07 \\
\hline Çoruh & 60.38 & 0.43 & 0.15 & 0.26 & 0.10 \\
\hline Doğu Karadeniz & 60.23 & 0.46 & 0.14 & 0.40 & 0.28 \\
\hline Batı Karadeniz & 28.81 & 0.44 & 0.15 & 0.16 & 0.21 \\
\hline
\end{tabular}

Çizelge 3'den de açıkça görülebildiği gibi, çok şiddetli rüzgâr erozyonunun yaşandığı en büyük ana akarsu havzalarında $\mathrm{W}_{\mathrm{F}}$ etmeninin en küçük havzalara oranla daha fazla olduğu belirlenmiştir. Yine rüzgâr erozyonuna karşı yüzey topraklarının direncinin belirlenmesinde önemli bir faktör olan $\mathrm{S}_{\mathrm{CF}}$ etmeni değerleri incelendiğinde ise en fazla alana sahip havzalarda daha fazla olduğu ortaya konulmuştur. Rüzgâr erozyonunda belirleyici ana parametrelerden bir diğeri olan $S_{\text {LRC }}$ etmeni göz önüne alındığında, en fazla alana sahip havzaların çok daha fazla duyarlı olduğu görülmektedir. Gerçekleştirilen bu detaylı analizlerden de görülebildiği gibi, çok şiddetli rüzgâr erozyonuna sahip havzalarda, alansal olarak miktarın fazla olması $W_{F}$ ve $S_{\text {LRC }}$ etmenlerine bağlı olarak açıklanabilir.

Doğal kaynak planlamasında yürütülecek stratejiye göre öncelikle çok şiddetli ve şiddetli rüzgâr erozyonu alanlarında gerekli önlemlerin alınabilmesi bakımından elde edilen sonuçlar yol gösterici niteliktedir. Ancak, erozyon sonucu izin verilebilir toprak kaybı tolerans değerleri su ve rüzgâr erozyonu için farklılık gösterebilir. $\mathrm{Bu}$ farklılık ana materyalin ayrışma hızı, bölgenin yağış ve sıcaklık ortalamaları ile erozyona maruz kalan toprağın derinliğine bağlı olarak azalabilir veya artabilir. Yürütülen bu çalışmada ülkemiz için rüzgâr erozyonu sonucu izin verilebilir toprak kaybı tolerans değerleri, Avrupa değerleri de esas alınarak 3 ton $\mathrm{ha}^{-1} \mathrm{yll}^{-1}$ olarak belirlenmiştir. Ancak ülkemizde rüzgâr erozyonunun kurak ve yarı kurak iklim bölgelerinin aeolian süreçlerinden birisi olmasına bağlı olarak toprak oluşum hızı yavaştır. Yine hızlandırılmış erozyon sonucu -eğimin düz ve düze yakın (\%0-2) olduğu alanlarda- söz konusu alanlar sığ toprak derinliğine sahiptir. Bu nedenle izin verilebilir rakamın daha düşük düzeyde tutulup alınacak mühendislik önlemlerinin bu rakama göre planlanması daha doğru olacaktır.

\section{SONUÇ}

$\mathrm{Bu}$ çalışma, rüzgâr erozyonu potansiyelini büyük ölçekte ülke genelinde değerlendirmek için UA ve CBS'nin etkin bir bileşkesi ile deneye dayalı yapılandırılan RWEQ modeli esas alınarak hazırlanmıştır. Neticede, RWEQ rüzgâr erozyonu tahmin modeli, Türkiye için yeni bir ulusal ölçekli rüzgâr erozyonu modeli oluşturmak ve sonuçlarını değerlendirmek için yersel ölçümler, gözlemler ve alan ölçekli model çalışmaları ile bütünleşik yapıda uygulanabilecek bir sistem mimarisine sahip olarak tasarlanmıştır. İnşa edilen RWEQ model sistemi ile birlikte Türkiye'de, ekilebilir araziler başta olmak üzere rüzgâr erozyonunun "nerede" ve "hangi oranda" olduğu sorularına cevap vermek tahmini olarak mümkün hale gelmiştir.

Yapılan çalışma, oldukça karmaşık dinamiklere sahip rüzgâr erozyonu olgusunu, karar vericiler ve planlayıcılar için daha somut hale getirmek adına önemli bir adımdır. Ayrıca yakın bir zaman diliminde, hali hazırda ayrıntılı ölçeklerde -örneğin parsel tabanlı yersel ölçümler- yürütülmekte olan, çalışmalar, projeler ve programlar yardımıla RWEQ model sonuçlarının ayarlama-ölçüleme ve doğrulama çalışmaları da kurulu sisteme dâhil edilecektir. Böylece RWEQ model sonuçlarının hassasiyetinin artırılmasıyla birlikte ulusal ölçekte rüzgâr erozyonu sonucu taşınan sediment 
miktarı ve rüzgâr erozyonu potansiyeline sahip alanlar gerçeğe yakın bir şekilde ortaya konularak yıllara sâri izlenimleri gerçekleştirilebilecek ve sürdürülebilir doğal kaynak planlamasında veri altlığı olarak kullanılabilecektir.

\section{KAYNAKLAR}

Acar R ve Dursun S, 2010. Vegetative Methods to Prevent Wind Erosion in Central Anatolia Region Int. J. of Sustainable Water \& Environmental Systems, Volume 1, No. 125 28.

Anonim., 2018. Roughness Length Classification of Corme Land Cover Classes, http://citeseerx.ist.psu.edu/viewdoc/download? doi=10.1.1.608.2707\&rep=rep1\&type $=$ pdf (Erişim Tarihi: 04.09.2018).

Basaran M, Uzun O, Erpul G, 2017a. Evaluation of Field Performance of BEST Aeolian Sediment Catcher in Sandy-loam Soil of Arid Zone of Turkey", Soil And Water Research, vol.12, pp.96-105.

Borrelli P, Lugato E, Montanarella L, Panagos P, 2016. A New Assessment of Soil Loss Due To Wind Erosion in European Agricultural Soils Using a Quantitative Spatially Distributed Modelling Approach 28: 335-344.

Boztoprak T, 2015. Kamulaştırmanın Parsel Sayısı ve Ortalama Parsel Büyüklüğüne Etkisi. S.Ü. Müh. Bilim ve Tekn. Derg., c.3, s.2, 2015 Selcuk Univ. J. Eng. Sci. Tech., v.3, n.2.

Fryrear DW, Bilbro JD, Saleh A, Schomberg H, Stout JE, Zobeck TM, 2000. RWEQ: improved wind erosion technology. Journal of Soil and Water Conservation 55: 183-189.

Fryrear DW, Saleh A, Bilbro JD, Schomberg HM, Stout JE, Zobeck TM, 1998. Revised Wind Erosion Equation (RWEQ). Technical Bulletin 1, Southern Plains Area Cropping Systems Research Laboratory, Wind Erosion and Water Conservation Research Unit, USDA-ARS.
Fryrear DW, Sutherland PL, Davis G, Hardee G, and Dollar M, 1999. Wind Erosion Estimates with RWEQ and WEQ. Pages 760-765.

Gillies RR, Carlson T, Cui J, Kustas W, Humes K, 1997. A verification of the 'triangle' method for obtaining surface soil water content and energy fluxes from remote measurements of the normalized difference vegetation index (NDVI) and surface radiant temperature. Int. J. Remote Sens. 18 (15), 3145-3166.

İnce K, 2017. Ulusal Ölçekte Rüzgâr Erozyonu Modellemesinde Rüzgâr Hızı ve Rüzgâr Yönü Parametrelerinin Elde Edilmesi. Yayınlanmamış Uzmanlık Tezi. Çölleşme ve Erozyonla Mücadele Genel Müdürlügüü, Ankara.

İnce K, Çelik S, Erpul G, 2019. Determination and Mapping of Wind Erosion Soil Susceptibility Variables at the National Scale in Turkey, Ege Univ. Ziraat Fak. Derg., 56 (1):109-120, DOI:10.20289/zfdergi.455581

İnce K, Şahin S, Erpul G, 2018. Yenilenmiş Rüzgâr Erozyonu Eşitliği İklim Faktörünün Ulusal Ölçekte Belirlenmesi. Toprak Su Dergisi 7/2 (Eylül 2018):12-20.

Okur O, 2010. Karapınar (Konya) Tarihsel Çölleşme Alanı Topraklarının Uzun Süreçte BademAkasya Altındaki Kalite Değişimleri. Çukurova Üniversitesi Fen Bilimleri Enstitüsü, Yüksek Lisans Tezi, Adana.

Youssef F, Visser S, Karssenberg D, Bruggeman A, Erpul G, 2012. Calibration of RWEQ in a patchy landscape; a first step towards a regional scale wind erosion model. Aeolian Research 3: 467-476.

Zobeck T.M, Van Pelt R.S, 2014. Wind Erosion. USDA Agricultural Research Service. Lincoln, Nebraska. Publications from USDAARS/UNL Faculty. Paper 1409, 209-227. 